Preface

\title{
Recent Advances in Thrombosis and Hemostasis-Part VII
}

\author{
Sam Schulman, MD, $\mathrm{PhD}^{1,2}$ \\ ${ }^{1}$ Department of Medicine, Thrombosis and Atherosclerosis Research \\ Institute, McMaster University, Hamilton, ON, Canada \\ ${ }^{2}$ Department of Obstetrics and Gynecology, The First I.M. Sechenov \\ Moscow State Medical University, Moscow, Russia
}

Semin Thromb Hemost 2021;47:621-622.

So long as little children are allowed to suffer, there is no true love in this world.

This 7th theme issue of the series of recent advances in thrombosis and hemostasis starts with a triad of review articles on venous thromboembolism (VTE) in children. Epidemiological studies demonstrate a peak of VTE during the first year of life and a second peak in adolescence. ${ }^{1}$ The disease is less well studied in children than in adults for several reasons, including the relatively lower incidence, increased difficulty to obtain consent, and the fact that new therapies are evaluated first in adults. There are many other differences between VTE in children and adults; for example, VTE is almost always provoked in the neonates, pulmonary embolism is relatively rare, and "unusual site" thrombosis is actually quite common. ${ }^{1}$ The first review, by White et al, focuses on children with community-acquired VTE, and who are seen in the emergency room. ${ }^{2}$ There are specific difficulties with the diagnosis in this population, often resulting in delays. Diagnostic options and therapeutic alternatives are discussed.

In severely ill children, among whom most of the VTE events of this age group occur, there is a need to provide thromboprophylaxis for those at high risk. Several factors have been identified as independent risk predictors, including length of stay, sepsis, and central venous catheters. Sochet et al reviews here the risk factors, risk stratification, options for thromboprophylaxis, diagnostic challenges, and acute treatment of VTE in critically ill children. ${ }^{3}$

In the third and last part, Branstetter et al present a systematic literature review of the data on non-vitamin $\mathrm{K}$ antagonist oral anticoagulants (NOACs) for prophylaxis or treatment of VTE in the pediatric population. ${ }^{4}$ Several studies are ongoing, but a few have been completed and published. The challenges include formulation for oral administration in children who are unable to swallow pills, the wide range of

Address for correspondence Sam Schulman, MD, PhD, Thrombosis Service, HHS-General Hospital, 237 Barton Street East, Hamilton, ON, L8L $2 \times 2$, Canada (e-mail: schulms@mcmaster.ca).
Isadora Duncan, dancer 1877-1927

body weights, and the potentially different pharmacokinetics, as we have learnt from the use of heparins in neonates. The results from the data presented are promising and it is just a matter of time until the NOACs will become standard of care for children as well.

Moving on to the better-studied adult population, a few contributions to this issue deal with risk factors for VTE. The use of glucocorticoids has been associated with increased risk of arterial as well as venous thrombotic events, but there is confounding by indication. The underlying diseases, for which glucocorticoids are indicated, are inflammatory or cancer and they also result in hypercoagulability. Whether the glucocorticoids render additional risk for VTE is reviewed by Simion et al. ${ }^{5}$ The authors also dive into the questions regarding importance of different routes of administration of the drug.

DNA methylation is one of the epigenetic processes that modulate gene transcription and it is sensitive to environmental changes, bringing us to the crossroads of genetics and environment. Global DNA methylation can be measured in peripheral blood. In an original study, Wang et al investigated whether there in an association between DNA methylation and unprovoked VTE in material obtained from a Swedish cohort study. ${ }^{6}$ Since increased DNA methylation could potentially have been the result of the VTE, the authors also analyzed the association with time to recurrent VTE.

Cancer is an unquestionable risk factor for VTE and is involved in about one-fifth of the patients with VTE. ${ }^{7}$ The various pathogenic mechanisms through which cancer causes VTE are reviewed by Costa and Araujo, who also review nontumor-related risk factors, biomarkers, and risk assessment models. ${ }^{8}$ The latter will need further refinement and individualization by applying machine learning could be the solution.

Deep vein thrombosis in the upper extremity is more commonly associated with cancer than thrombosis in the leg. This leads us to the review of upper extremity deep vein thrombosis by Yuen et al. ${ }^{9}$ For the diagnostic algorithm, they discuss the Constans score, which probably is not very (c) 2021. Thieme. All rights reserved. Thieme Medical Publishers, Inc., 333 Seventh Avenue, 18th Floor, New York, NY 10001, USA
DOI https://doi.org/ 10.1055/s-0041-1725945. ISSN 0094-6176.
Thrombosis and Hemostasis-

Part VII; Guest Editor: Sam

Schulman, MD, PhD 
well known or utilized, and how it may be combined with the D-dimer. Ultrasonography is the widely accepted method for diagnosis, although some segments of the venous system are obscured and difficult to visualize. The dilemma of how to manage asymptomatic arm vein thrombosis is highlighted by the authors, who also review prophylaxis, treatment, postthrombotic syndrome, and management of thoracic outlet syndrome with deep vein thrombosis.

For patients with pulmonary embolism, the dreaded longterm sequel is chronic thromboembolic pulmonary hypertension (CTEPH). The diagnosis of CTEPH requires a high degree of suspicion and is therefore often delayed by 1 year or more. It is thus important to apply algorithms for whom to screen for CTEPH and how to do it. Boon et al are here deliberating extensively on this problem and present the InShape II algorithm for this purpose. ${ }^{10}$ It is still under evaluation but seems very practical to select which patients to refer for echocardiography at 3 months after pulmonary embolism.

In the last part of this issue, we have four articles dealing with different aspects of anticoagulation. First, Miziara et al present a systematic literature review of anticoagulation management in association with dental implant surgery. ${ }^{11}$ One of the difficulties they met was that many studies included different types of dental procedures, including simple tooth extractions. Furthermore, standardized evaluation of bleeding complications was often lacking. Nevertheless, in the five studies that finally were included in the analysis, the incidence of bleeding was very low and not significantly higher among those maintained on anticoagulation than in those with interrupted anticoagulation.

Second, Aibar and Schulman have performed a meta-analysis of outcomes in patients with arterial thrombotic antiphospholipid syndrome (APS), according to six different antithrombotic regimens used. ${ }^{12}$ Eleven studies were included. It was already known that NOACs must not be used for patients with triple positive APS, but in case of specifically arterial thrombotic manifestations, the increased risk of recurrent events is probably higher than with vitamin $\mathrm{K}$ antagonists even for single- or double-positive APS. It seems, however, that combined antithrombotic therapy is more effective than vitamin $\mathrm{K}$ antagonist alone, without compromising with safety.

Third, for patients with mechanical heart valves or left ventricular assist devices, vitamin $\mathrm{K}$ antagonists are the standard of care for long-term management and failures have been reported when using NOACs. Liesdek et al have now reviewed systematically preclinical and clinical study results. $^{13}$ Current and future developments include less thrombogenic device materials and newer anticoagulants that target components of the contact activation system.

Fourth, when to discontinue anticoagulation for patients at the end of life is a difficult decision, and often the treatment is continued until death without a structured decision process. Huisman et al performed a mixed methods analysis of physician opinions and present interesting results here. ${ }^{14}$ Perhaps the most difficult part for the treating physician is to understand how a decision in this situation will affect the quality of life for the patient.

Hopefully, this compilation of articles, mostly reviews, spanning from pediatric thrombosis and risk factors for VTE to specific problems with anticoagulation therapy will provide something of interest for every reader of Seminars in Thrombosis and Hemostasis. The articles are by authors from the United States, Canada, Australia, Brazil, the Netherlands, Sweden, Portugal, and Italy, thus with a fine international distribution, as is appropriate for an international journal.

\section{Conflict of Interest}

None declared.

\section{References}

1 Chalmers EA. Epidemiology of venous thromboembolism in neonates and children. Thromb Res 2006;118(01):3-12

2 White M, Betensky M, Lawson SL, Goldenberg NA. Community onset venous thromboembolism in children: pediatric emergency medicine perspectives. Semin Thromb Hemost 2021;47(06):623-630

3 Sochet AA, Kiskaddon A, Betensky M, Goldenberg NA. Venous thromboembolism among critically ill children. Semin Thromb Hemost 2021;47(06):631-642

4 Branstetter JW, Kiskaddon A, King MA, et al. Efficacy and safety of non-vitamin $\mathrm{k}$ antagonist oral anticoagulants in pediatric venous thromboembolism treatment and thromboprophylaxis: a systematic review of the literature. Semin Thromb Hemost 2021; 47(06):643-653

5 Simion C, Campello E, Bensi E, et al. Use of glucocorticoids and risk of venous thromboembolism: a narrative review. Semin Thromb Hemost 2021;47(06):654-661

6 Wang X, Memon AA, Palmer K, et al. The association between blood-based global DNA methylation and venous thromboembolism. Semin Thromb Hemost 2021;47(06):662-668

7 Heit JA, O'Fallon WM, Petterson TM, et al. Relative impact of risk factors for deep vein thrombosis and pulmonary embolism: a population-based study. Arch Intern Med 2002;162(11):1245-1248

8 Costa J, Araujo A. Cancer-related venous thromboembolism: from pathogenesis to risk assessment. Semin Thromb Hemost 2021;47 (06):669-676

9 Yuen HLA, Tran H, Chunilal S. Upper extremity deep vein thrombosis: current knowledge and future directions. Semin Thromb Hemost 2021;47(06):677-691

10 Boon GJAM, Huisman MV, Klok FA. Why, whom and how to screen for CTEPH after acute pulmonary embolism. Semin Thromb Hemost 2021;47(06):692-701

11 Miziara LNB, Sendyk WR, Ortega KL, Gallottini M, Sendyk DI, Martins F. Risk of bleeding during implant surgery in patients taking antithrombotics: a systematic review. Semin Thromb Hemost 2021;47(06):702-708

12 Aibar J, Schulman S. Arterial thrombosis in patients with antiphospholipid syndrome: a review and meta-analysis. Semin Thromb Hemost 2021;47(06):709-723

13 Liesdek OCD, Urbanus RT, de Heer LM, et al. Alternatives for vitamin $\mathrm{K}$ antagonists as thromboprophylaxis for mechanical heart valves and mechanical circulatory support devices: a systematic review. Semin Thromb Hemost 2021;47(06):724-734

14 Huisman BAA, Geijteman ECT, Kolf N, et al. Physicians' opinions on anticoagulant therapy in patients with a limited life expectancy. Semin Thromb Hemost 2021;47(06):735-744 